OPEN ACCESS

Edited by: Lorys Castelli, University of Turin, Italy

Reviewed by: Carisa Parrish,

Johns Hopkins Medicine, United States Sarah VerLee, Nationwide Children's Hospital, United States

*Correspondence: Mira D. H. Snider mdh0054@mix.wvu.edu

Specialty section: This article was submitted to Health Psychology, a section of the journal Frontiers in Psychology

Received: 14 April 2021 Accepted: 09 November 2021 Published: 09 December 2021

Citation: Snider MDH, Young S, Enlow PT, Ahrabi-Nejad C, Aballay AM and

Duncan CL (2021) Coping in

Pediatric Burn Survivors and lts Relation to Social Functioning and Self-Concept.

Front. Psychol. 12:695369 doi: 10.3389/fpsyg.2021.695369

\section{Coping in Pediatric Burn Survivors and Its Relation to Social Functioning and Self-Concept}

\author{
Mira D. H. Snider ${ }^{1,2 *}$, Sarah Young ${ }^{1}$, Paul T. Enlow ${ }^{3,4}$, Corrine Ahrabi-Nejad ${ }^{1}$, \\ Ariel M. Aballay ${ }^{2}$ and Christina L. Duncan ${ }^{1,2}$
}

${ }^{1}$ Department of Psychology, West Virginia University, Morgantown, WV, United States, ${ }^{2}$ Department of Surgery, Burn Trauma Center, Western Pennsylvania Hospital, Allegheny Health Network, Pittsburgh, PA, United States, ${ }^{3}$ Center for Healthcare Delivery Science, Nemours Children's Health System, Wilmington, DE, United States, ${ }^{4}$ Department of Pediatrics, Sidney Kimmel Medical College, Thomas Jefferson University, Philadelphia, PA, United States

Pediatric burn survivors experience increased risk for bullying, stigmatization, body image concerns, and problematic social functioning. Although coping behaviors are associated with engagement in social supports and positive self-concept in multiple pediatric illness populations, their relation has not been examined in pediatric burns. This study examined coping in relation to social functioning and self-concept in 51 pediatric burn survivors aged $7-17$ years $(M=12.54 ; S D=2.65)$. Survivors and their caregivers completed the Child Coping Strategies Checklist (CCSC; youth report); the Burn Injury Social Questionnaire (BISQ; parent and youth report); and the Piers-Harris Children's Self-Concept Scale-2 (PH-2; youth report). Associations between coping, social functioning, self-concept, demographic features, and burn injury characteristics were examined via bivariate correlations. Hierarchical linear regressions examined whether coping strategies predicted social functioning and youth self-concept beyond burn injury and demographic variables. Social functioning concerns were positively correlated with total body surface area (TBSA; $r=0.63$ and 0.40 , respectively). TBSA was the only significant predictor of parent-reported social concerns $(\beta=0.65, p<0.001)$. Greater distraction coping predicted fewer youthreported social concerns $(\beta=-0.39, p=0.01)$. Greater active coping $(B=0.67, p=0.002)$ and lower avoidance coping $(B=-0.36, p=0.03)$ predicted better youth-reported selfconcept. This study advances our understanding of coping as potentially protective for psychosocial adjustment. Clinicians working with child burn survivors should incorporate active coping interventions into treatment. Further research including larger and more diverse samples is needed to understand the role of coping approaches on psychological adjustment during burn healing.

Keywords: adaptive coping, pediatrics, burn survivors, social functioning, self-concept 


\section{INTRODUCTION}

Burns are among the leading causes of injury and unintentional death in the United States (American Burn Association, 2018). Pediatric populations are particularly vulnerable to burn injuries, with nearly a quarter of burn incidents in the United States occurring in children under 15 years of age (American Burn Association, 2018). Although many burn injuries are not treated medically or can be treated in outpatient settings, severe injuries require hospitalization or transfer to a burn center for critical care (Krishnamoorthy et al., 2012). Treatment of burn injuries can include dressing changes, wound cleansing, medicated salve, pain management, skin grafting, physical and occupational therapies, and pressurized garments (Gill, 2010; Krishnamoorthy et al., 2012). Consequentially, burn care can be medically extensive, painful, and last months to years.

Along with their physical repercussions, burns are associated with impairments in psychosocial functioning that hinder healing, long-term adjustment, and overall well-being (Lavigne and Faier-Rouman, 1992; Pardo et al., 2008; Gill, 2010; Enlow et al., 2019). One domain of psychosocial functioning that can be specifically impacted by burns is social functioning. A systematic review of 75 articles focusing on the psychosocial outcomes of pediatric burn injuries revealed that survivors were at an increased risk for difficulties in social functioning several years post-burn (Bakker et al., 2013). Another study (Andersson et al., 2003) identified that parents of pediatric burn survivors perceived their children as having reduced social initiative, while teachers perceived students who survived burns as having a less prosocial orientation. Additionally, problems with peers were more common in children who had sustained burn injuries compared to the general population (Willebrand et al., 2011). Despite these findings, the extant literature on social adjustment in pediatric burns is not extensive, and this is an area in need of additional study.

Although not all burn survivors experience long-term psychosocial concerns (e.g., Koon, 1993; Bakker et al., 2013), the trauma of the injury itself, the pain of burn care, and potential physical outcomes (e.g., disfigurement, limited mobility) place youth at substantial risk for maladjustment (e.g., Gill, 2010; Kazis et al., 2017). It is critical for caregivers to support pediatric burn survivors such that they may engage in effective coping skills to ameliorate or prevent adverse psychological experiences (Meijer et al., 2002; Gill, 2010; Enlow et al., 2019). Compas et al. (2001) defines coping as "conscious, volitional efforts to regulate emotion, cognition, behavior, physiology, and the environment in response to stressful events or circumstances." Specific psychosocial stressors that may be targeted by coping interventions in pediatric burn survivors include changes to social functioning and self-concept.

The physical sequelae from burns (e.g., visible scarring) can affect the self-concept of burn survivors, particularly during childhood and early adolescence, which is a formative period for a child's sense of self (Koon, 1993). Youth who experience disfigurement from burn injuries have reported deficits in psychosocial functioning, including lower self-esteem, difficulties with self-concept and social skills, and higher levels of anxiety (Gill, 2010). A key factor that influences adjustment in pediatric burn survivors is the reaction of peers and those in public. Burn survivors are more likely to adjust poorly if peers react negatively toward their physical disfigurement (LeDoux et al., 1996), and survivors who experience debilitating physical symptoms may be limited in their social participation (Kazis et al., 2017). Conversely, psychosocial support from family and a trauma-informed healthcare team during the acute phase following a burn injury is important for promoting healthy adjustment (De Sousa, 2010; Bakker et al., 2013).

Coping behaviors are a significant predictor of self-esteem, social skills, social anxiety, and behavioral difficulties in chronically ill patients broadly (Meijer et al., 2002). Negative coping strategies, such as avoidance, have been associated with increased social difficulties in pediatric patients with neonatal brachial plexus injuries (Mentrikoski et al., 2015). Similarly, a cross-sectional study on youth with spinal cord injuries revealed an association between avoidant coping strategies, lower quality of life, and higher anxiety and depressive symptoms (Smith et al., 2013). In contrast, active coping strategies (i.e., seeking social support, problem solving, and openly talking about stressors) are most effective for promoting the psychosocial adjustment of chronically ill pediatric patients (Meijer et al., 2002) and a key to family functioning and support in pediatric oncology patients (Trask et al., 2003; Martin et al., 2012). In the context of pediatric burns, adaptive coping strategies are negatively associated with post-traumatic stress symptoms (Enlow et al., 2019), whereas internalizing (e.g., rumination, fixating on anxieties) and externalizing coping behaviors (e.g., screaming, breaking things) have been related to greater panic and general anxiety disorder symptoms (Rimmer et al., 2015).

Although there are several studies on the psychosocial impacts of pediatric burns, the relations among coping behaviors, social functioning, and self-concept are not well understood in this population. The current study expands upon extant research by addressing the following aims: (1) examine associations among coping behaviors, social functioning, selfconcept, and burn injury-related variables; (2) investigate the extent to which coping strategies predict social functioning; and (3) assess the extent to which coping strategies predict self-concept in pediatric burn survivors.

\section{MATERIALS AND METHODS}

\section{Participants}

Fifty-one pediatric burn survivors $(M$ age $=12.54 ; S D=2.65$ ) and their primary caregivers participated. Families were recruited as part of a larger multi-project (e.g., Enlow et al., 2019) study examining the psychosocial outcomes of pediatric burn survivors. Eligible survivors were 7-17 years of age and had sustained a burn requiring medical treatment at least 1 month before recruitment. Survivors and caregivers were English speaking (measures validated only in English). Exclusion criteria included the child or caregiver having significant cognitive impairment, 
as reported by the primary caregiver or medical team that would preclude completion of study measures.

\section{Procedure}

Researchers obtained hospital and university Institutional Review Board approval before project initiation. Participants were recruited during outpatient clinic appointments at two hospitals in Pennsylvania $(n=14)$ and Ohio $(n=4)$ and during registration for a summer camp in Pennsylvania for pediatric burn survivors $(n=22)$. A recruitment letter and informed consent forms were mailed to burn survivors in the Pennsylvania hospital's burn registry database who met inclusion criteria but were not approached in clinic or at camp (e.g., no longer required follow-up care), which yielded additional participants $(n=11)$.

Caregivers and survivors recruited from clinic and camp each independently completed a questionnaire packet. Caregiver packets included the Family Information Form and Burn Injury Social Questionnaire (BISQ), while survivor packets included the Child Coping Strategies Checklist (CCSC), BISQ, and the Piers-Harris Children's Self-Concept Scale-2 (PH-2). Burn survivors recruited by letter from the hospital database were asked to contact research staff if interested in participating. They completed measures sent by mail, which were addressed individually for parent and child so that their responses could remain confidential from one another. Research staff also obtained data through medical records and the burn registry database.

\section{Measures}

\section{Family Information Form}

The Family Information Form was designed for this study to obtain demographic information (i.e., gender, age, race, education, and socioeconomic status) from caregivers.

\section{Chart Review Form}

Research staff documented relevant medical history (i.e., burn characteristics, total body surface area of the burn; TBSA, associated surgeries and hospital stays, and scarring and disfigurement) for patients on the Chart Review Form.

\section{Child Coping Strategies Checklist}

The CCSC (Ayers et al., 1996) is a 52-item self-report questionnaire that measures coping behaviors over the past month when trying to solve problems. Items in this measure are rated on a 4-point Likert scale ranging from 1 (never) to 4 (most of the time), yielding four subscales: active coping, distraction strategies, avoidance strategies, and support seeking strategies. In our sample, internal consistency was high for the active coping $(\alpha=0.93)$ and support seeking subscales ( $\alpha=0.88$ ), good for the avoidance strategies subscale $(\alpha=0.75)$, and somewhat questionable for the distraction subscale $(\alpha=0.67)$.

\section{Burn Injury Social Questionnaire}

The BISQ is a brief, 10-item self-report screening questionnaire that was devised for this study to assess social functioning after a burn injury (e.g., "Kids tease me about the way I look"; "It is hard for me to have friends or dates because of my burn injury"). Items in this measure are rated on a fourpoint Likert scale ranging from 1 (not at all true) to 4 (very true). Parent- and child-report parallel versions are available; both versions have a Flesch-Kincaid grade level of below 1.0 , suggesting that they are very easy to read and understand. Although this measure has not yet been validated, the items are face valid. Cronbach's alpha for the current sample suggests good internal consistency for the BISQ-P $(\alpha=0.79)$ and BISQ-Y $(\alpha=0.72)$. A total score is calculated for analyses, with higher scores representing more problematic social concerns.

\section{Piers-Harris Children's Self-Concept Scale-2}

The PH-2 (Piers and Herzberg, 2002) is a common, validated measure evaluating self-concept in youth. This 60-item questionnaire is rated using a yes/no format and is divided into six subscales: behavioral adjustment, intellectual and school status, physical appearance and attributes, freedom from anxiety, popularity, and happiness and satisfaction. The total standardized $t$-score for the PH-2 was used in analyses $(\alpha=0.89$ for our sample); higher scores represent higher overall self-concept.

\section{Statistical Analysis}

Bivariate correlations, independent samples $t$-tests, and ANOVA were used to examine the associations among coping behaviors, social functioning, self-concept, and demographic and burn injury-related variables (Aim 1). Hierarchical linear regression was used to assess whether coping strategies predicted social functioning (Aim 2) and self-concept (Aim 3). Demographic and burn injury-related variables significantly associated with self-concept and social functioning in bivariate analyses were included as covariates in the respective regression models.

\section{RESULTS}

\section{Demographics/Descriptive Statistics}

Frequencies (Table 1) and descriptive statistics (Table 2) for demographic, clinical, and variables are reported for our sample. Due to the non-normal distribution of the family income data, participants were divided into quartiles (1st quartile $=\leq \$ 29.9 \mathrm{k}$, 2nd quartile $=\$ 30 \mathrm{k}-\$ 49.9 \mathrm{k}$, 3rd quartile $=\$ 50 \mathrm{k}-\$ 89$, and 4 th quartile $=\geq \$ 90 \mathrm{k}$ ) for analyses. The median income was $\$ 40-\$ 49.9 \mathrm{k}$ and the interquartile range was $\$ 60-\$ 69.9 \mathrm{k}$. The most common cause of burn was thermal (40.4\%), followed by scald $(32.7 \%)$. The average TBSA among participants was moderate (i.e., 9.19\%), with approximately one-third having received skin graft surgery. Though the sample varied greatly with respect to time since injury (range $=1-141.5$ months), participants completed study measures about 33 months, on average, after their injury. Examination of $\mathrm{PH}-2$ total scores revealed that approximately $4 \%(n=2)$ of participants had borderline low self-concept T-scores $(\geq 1$ SD but $<2$ SD below 
TABLE 1 | Participant $(N=52)$ demographics.

\begin{tabular}{|c|c|c|}
\hline Variable & Value & $n(\%)$ \\
\hline \multirow[t]{2}{*}{ Gender } & Male & $33(63.5 \%)$ \\
\hline & Female & 19 (36.5\%) \\
\hline \multirow[t]{2}{*}{ Race } & White & 46 (88.5\%) \\
\hline & Non-White & $6(11.5 \%)$ \\
\hline \multirow[t]{11}{*}{ Yearly family income } & $<\$ 10 \mathrm{k}$ & $3(5.8 \%)$ \\
\hline & $\$ 10 k-\$ 19.9 k$ & $5(9.6 \%)$ \\
\hline & $\$ 20 k-\$ 29.9 k$ & $6(11.5 \%)$ \\
\hline & $\$ 30 k-\$ 39.9 k$ & 5 (9.6\%) \\
\hline & $\$ 40 k-\$ 49.9 k$ & $7(13.5 \%)$ \\
\hline & $\$ 50 k-\$ 59.9 k$ & $4(7.7 \%)$ \\
\hline & $\$ 60 k-\$ 69.9 k$ & $3(5.8 \%)$ \\
\hline & $\$ 70 k-\$ 79.9 k$ & $4(7.7 \%)$ \\
\hline & $\$ 80 k-\$ 89.9 k$ & $6(11.5 \%)$ \\
\hline & $\$ 90 k-\$ 99.9 k$ & 3 (5.8\%) \\
\hline & $>\$ 100 k$ & $5(9.6 \%)$ \\
\hline \multirow[t]{6}{*}{ Cause of burn } & Thermal & $21(40.4 \%)$ \\
\hline & Scald & 17 (32.7\%) \\
\hline & Contact & $8(15.4 \%)$ \\
\hline & Electrical & $1(1.9 \%)$ \\
\hline & Friction & $1(1.9 \%)$ \\
\hline & Other & $1(1.9 \%)$ \\
\hline Received skin graft & Yes & 35 (32.7\%) \\
\hline Visible burn injury & Yes & $46(92.0 \%)$ \\
\hline
\end{tabular}

Thermal= burn caused by external heat source (e.g., flame); Scald= burn caused by contact with heated liquids (e.g., coffee); Contact=burn caused by contact with heated objects (e.g., hot iron); Electrical= burn caused by contact with an electric current (e.g., exposed wire); and Friction = burn caused by rubbing against another surface (e.g., treadmill).

TABLE 2 | Descriptive statistics.

\begin{tabular}{|c|c|c|c|c|c|}
\hline & $n$ & Mean & SD & Min & Max \\
\hline \multicolumn{6}{|l|}{ Clinical variables } \\
\hline Time since burn (in months) & 52 & 33.38 & 44.83 & 1.02 & 141.53 \\
\hline Total TBSA ${ }^{a}$ & 47 & 9.19 & 11.33 & 1.00 & 58.50 \\
\hline \multicolumn{6}{|l|}{ Psychosocial variables } \\
\hline $\mathrm{BISQ}^{\mathrm{b}}$ total (parent) & 47 & 4.96 & 5.24 & 0.00 & 25.00 \\
\hline BISQ total (youth) & 45 & 5.18 & 4.74 & 0.00 & 18.00 \\
\hline $\operatorname{CCSC}^{\circ}-$ active & 46 & 2.65 & 0.65 & 1.25 & 3.96 \\
\hline CCSC - distraction & 46 & 2.50 & 0.55 & 1.44 & 3.89 \\
\hline CCSC - avoidance & 46 & 2.44 & 0.57 & 1.42 & 3.75 \\
\hline CCSC - support & 46 & 2.31 & 0.78 & 1.00 & 3.56 \\
\hline $\mathrm{PH}-2^{\mathrm{d}}$ total self-concept & 48 & 47.77 & 9.79 & 11.00 & 60.00 \\
\hline
\end{tabular}

Total body surface area.

${ }^{\circ}$ Burn injury social questionnaire (BISQ).

${ }^{\circ}$ Child coping strategies checklist (CCSC).

${ }^{d}$ Piers-harris children's self-concept scale - 2nd edition (PH-2).

the mean) and around $2 \%(n=1)$ had significantly low selfconcept T-scores ( $\geq 2$ SD below the mean).

\section{Bivariate Analyses}

Results from bivariate correlations are presented in Table 3. To explore potential covariates $(p<0.05)$ for regression models, we examined bivariate correlations of age, TBSA, and time since burn with each of our primary outcomes (BISQ and PH-2 total scores). TBSA was positively associated with parent report $(r=0.63, p<0.001)$ and youth report on the BISQ $(r=0.40, p=0.008)$. Youth report on the $\mathrm{PH}-2$ was negatively associated with age $(r=-0.34, p=0.04)$.

Correlations among primary study variables revealed that youth report on the $\mathrm{PH}-2$ was negatively associated with youth reports on the BISQ $(r=-0.42, p=0.005)$ and positively associated with youth use of active coping strategies $(r=0.41, p=0.007)$. The use of active coping strategies was positively correlated with the use of distraction $(r=0.35, p=0.017)$, avoidance $(r=0.61$, $p<0.001)$, and social support coping strategies $(r=0.66, p<0.001)$. The use of social support coping was also positively correlated with avoidance coping $(r=0.45, p=0.002)$. As expected, BISQparent and BISQ-youth scores were positively correlated $(r=0.47$, $p=0.001)$.

\section{Between-Group Comparisons}

Independent-samples $t$-tests suggested that youth who had skin graft surgery reported more burn-related social problems on the BISQ $(M=6.23, S D=5.28)$ than youth without a skin graft $[M=2.86, S D=1.75 ; t(40.78)=-3.19, p=0.003 ; d=0.86]$. There were no significant differences in youth $\mathrm{PH}-2$ scores or parent BISQ scores between youth who did and did not have a skin graft. Male and female participants did not differ significantly in self-concept, or youth and parent report of burn-related social problems. Results from one-way ANOVA's suggested BISQ and youth PH-2 scores were not statistically significant between family income quartiles ( $p$ 's $>0.05$ ).

\section{Regression Analyses}

Hierarchical linear regression was used to examine whether coping strategies predicted (1) youth and (2) parent reports on the BISQ, as well as (3) youth report on the PH-2. Covariates (TBSA, presence of a skin graft) were entered in step one of the regression analysis, while all coping subscales from the CCSC were entered in step two. Results from three hierarchical linear regression analyses are reported in Table 4.

The first model examined whether coping variables predicted youth reports on the BISQ. The full model was statistically significant $[F(6,36)=4.01, p=0.004]$ and accounted for $30 \%$ of the variance in youth reports of social problems. In the full model, greater use of distraction coping predicted fewer youth-reported burn-specific social problems $(\beta=-0.39, p=0.01)$. Active, avoidance, and social support coping were not statistically significant predictors of youth reports on the BISQ. The presence of a skin graft $(\beta=0.34, p=0.02)$ and TBSA $(\beta=0.31, p=0.03)$ also significantly predicted more youth-reported burn-specific social problems on the BISQ.

The second model examined whether coping variables predicted parent reports on the BISQ. The full model was statistically significant $[F(5,37)=5.79, p<0.001]$ and accounted for $36 \%$ of the variance in parent reports of burn-specific social problems. In the full model, a greater TBSA predicted more parent reports of burn-specific social problems $(\beta=0.65$, $p<0.001)$. None of the coping strategies were statistically significant predictors of parent reports on the BISQ.

The final model examined whether coping variables predicted youth self-concept as measured by the PH-2. The full model 
TABLE 3 | Bivariate correlations.

\begin{tabular}{|c|c|c|c|c|c|c|c|c|c|}
\hline & Age & $\begin{array}{l}\text { Active } \\
\text { coping }\end{array}$ & $\begin{array}{l}\text { Distraction } \\
\text { coping }\end{array}$ & $\begin{array}{l}\text { Avoidance } \\
\text { coping }\end{array}$ & $\begin{array}{l}\text { Social support } \\
\text { coping }\end{array}$ & BISQ - parent & BISQ - youth & PH2 - total & TBSA \\
\hline Active coping & -0.10 & --- & & & & & & & \\
\hline Distraction coping & 0.04 & $0.35^{*}$ & --- & & & & & & \\
\hline Avoidance coping & -0.16 & $0.61^{* * * *}$ & 0.27 & --- & & & & & \\
\hline Social support coping & -0.14 & $0.66^{* * * *}$ & 0.21 & $0.45^{* *}$ & --- & & & & \\
\hline $\mathrm{BISQ}^{\mathrm{a}}$ - parent & -0.20 & 0.03 & -0.08 & 0.09 & -0.01 & --- & & & \\
\hline $\mathrm{BISQ}^{\mathrm{a}}$ - youth & -0.01 & -0.10 & 0.28 & 0.07 & 0.07 & $0.47^{* *}$ & --- & & \\
\hline $\mathrm{PH} 2^{\mathrm{b}}-$ total & $-0.34^{*}$ & $0.37^{*}$ & 0.24 & -0.03 & 0.15 & -0.17 & $-0.46^{* *}$ & --- & \\
\hline $\mathrm{TBSA}^{\mathrm{c}}$ & -0.07 & 0.01 & 0.10 & 0.04 & 0.04 & $0.63^{* * * *}$ & $0.40^{* *}$ & 0.08 & --- \\
\hline Time since burn & 0.17 & 0.06 & 0.17 & 0.08 & 0.10 & 0.08 & -0.27 & -0.02 & 0.09 \\
\hline
\end{tabular}

${ }^{*} p<0.05 ;{ }^{* *} p<0.01 ;{ }^{* * *} p<0.001$.

${ }^{a}$ Burn injury social questionnaire.

bPiers-harris children's self-concept scale - 2nd edition.

${ }^{\circ}$ Total body surface area.

TABLE 4 | Hierarchical linear regressions.

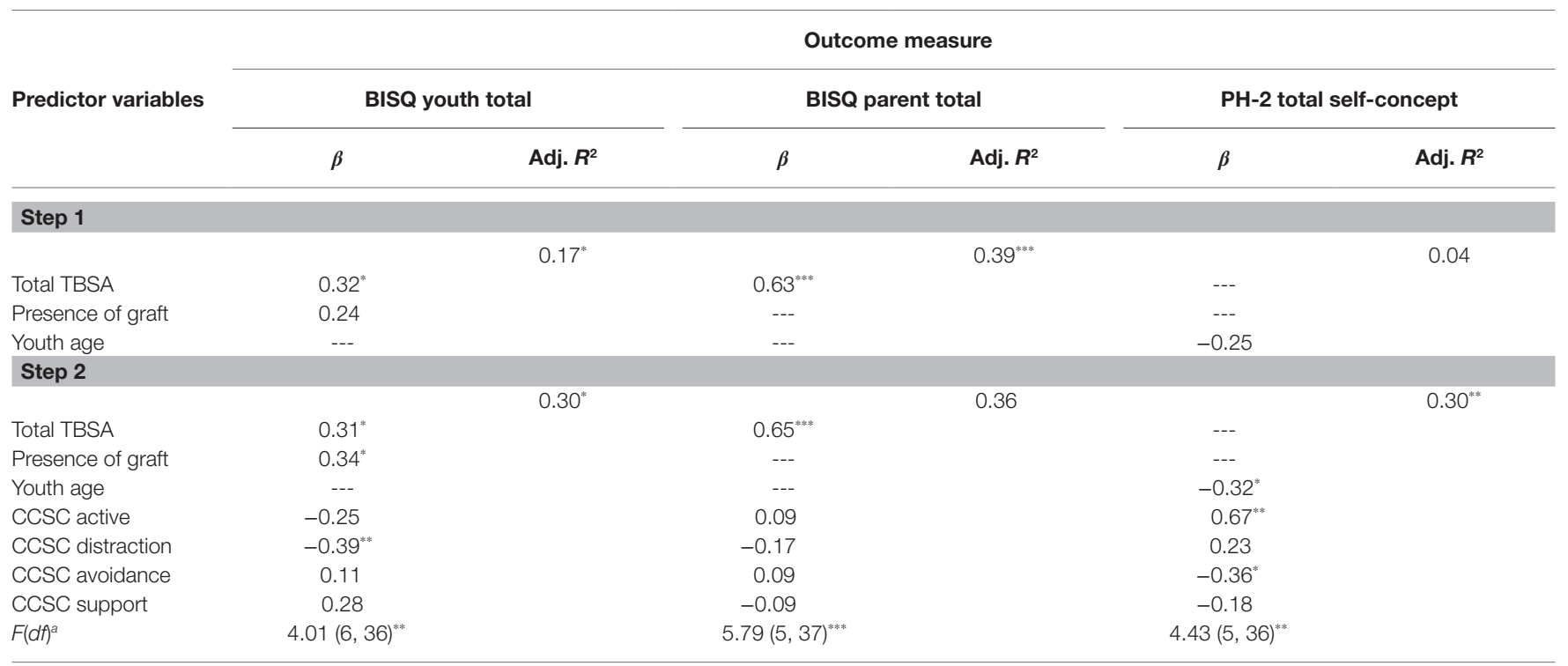

a F-ratio for full model.

" $p<0.05 ;{ }^{* *} p<0.01 ;{ }^{* * *} p<0.001$.

was statistically significant $[F(5,36)=4.43, p=0.003]$ and accounted for $30 \%$ of the variance in youth self-concept. In the full model, greater use of active coping strategies predicted better youth self-concept $(\beta=0.67, p=0.002)$, while greater use of avoidance coping predicted worse youth self-concept $(\beta=-0.36, p=0.03)$. Older youth also reported worse selfconcept $(\beta=-0.32, p=0.02)$. None of the other coping strategies were statistically significant predictors of youth reports on the $\mathrm{PH}-2$.

\section{DISCUSSION}

Burn injuries in children can lead to substantial psychosocial concerns stemming from the trauma of the injury itself, its painful treatment, and its physical sequelae. Thus, pediatric burn survivors are at an increased risk of negative psychosocial outcomes such as anxiety, depression, acute stress disorder, PTSD, and deficits in self-concept and social functioning (Landolt et al., 2009; Bakker et al., 2013; Kazis et al., 2017). To date, there is limited research on how coping relates to self-concept and social functioning in these youth (LeDoux et al., 1996; Gill, 2010). This study investigated associations between coping behaviors, social functioning, self-concept, and individual characteristics in pediatric burn survivors, with a particular focus on whether specific types of coping predicted social functioning and self-concept.

Our first hypothesis that there would be associations between coping, social functioning, self-concept, and burn injury-related variables was partially supported. Lower youth self-concept was associated with more youth reports of burn-specific social problems and older survivor age. Higher self-concept was 
associated with greater use of active coping strategies. Youth and parent reports of more burn-specific social problems were also associated with higher TBSA.

Significant inter-correlations between coping subscales in our sample suggest that pediatric burn survivors rely on multiple forms of coping, rather than one specific or predominant coping strategy. This is similar to the findings of Camisasca et al. (2017), who found that youth who displayed secure attachment employed multiple coping strategies (i.e., active, social support, distraction, and avoidance) when faced with stressors. Likewise, Heffer and Willoughby (2017) alluded to the importance of coping flexibility with different coping strategies for different situations, which could explain why we obtained significant inter-correlations among coping strategies. The pattern of correlations was inconsistent, however, as not all coping subscales were correlated significantly with each other. It may be that inter-correlations were identified between active coping and social support, distraction, and avoidance coping because the use of active coping strategies involves attempts to reduce negative feelings and outcomes, which could consist of behaviors that resemble social support, distraction, and avoidance. Future research should continue to explore inter-correlations between use of different coping strategies to advance our understanding of the types of coping used in pediatric burn survivors and which combinations are most beneficial.

Our remaining hypotheses regarding the role of coping strategies as predictors of social functioning and self-concept were also partially supported. After controlling for burn injury variables and use of other coping strategies, greater use of distraction coping predicted fewer youth reports of burn-specific social problems. Similarly, less use of avoidance coping strategies and greater use of active coping strategies predicted lower youth self-concept after controlling for youth age and other coping strategies. Other coping strategies were not significant predictors of social functioning or self-concept in our sample. These findings align with prior research that suggests that the use of adaptive coping (e.g., active, social support, and distraction) is most effective in influencing positive youth psychosocial outcomes in youth with chronic illnesses (Meijer et al., 2002). Simultaneously, these results build upon the previous literature that found adaptive coping to be associated with positive parental mental health outcomes (Enlow et al., 2019). Adaptive coping is likely most effective because it requires youth to confront setbacks through problem solving and being cognizant of their thoughts and feelings toward the situation. Avoidance coping involves cognitive or behavioral strategies to avoid, deny, or minimize stressors and is associated with negative psychosocial outcomes (Smith et al., 2013; Mentrikoski et al., 2015). Consistent with past research, greater use of avoidance coping strategies predicted lower self-concept in pediatric burn survivors. However, use of avoidance coping was not significantly associated with burn-specific social problems in the current study. It may be that avoiding social problems with peers is less problematic and potentially adaptive in certain situations (e.g., staying away from bullies). Alternatively, this null finding may be due to the low statistical power of this study stemming from the small sample size.
Although the current study was conducted in the context of pediatric burns, our findings highlight the importance of adaptive coping strategies across illness populations. Empirically supported coping skills interventions can be delivered to help promote the use of adaptive coping strategies (e.g., open communication, conflict resolution, and problem solving; Jefferson et al., 2011). These interventions have been advantageous in other pediatric populations with chronic conditions, such as Type 1 diabetes (Hilliard and Hood, 2011). Taken together with the findings of the current study, it is likely that interventions which aim to increase the use of adaptive coping strategies (e.g., active, social support, and distraction), while decreasing the use of coping strategies associated with adverse psychosocial outcomes (e.g., avoidance coping) may be beneficial if tailored to pediatric burn survivors. In particular, a tailored intervention might focus on many of the same topics common to coping skills training (e.g., problem-solving, communication, and dealing with stress), but also target specific coping skills within burn-related scenarios (e.g., receiving wound care, responding to staring and bullying).

Consistent with prior research on burn-related psychosocial outcomes (Gill, 2010; Kazis et al., 2017), youth who had a skin graft stemming from a deeper burn and likely more scarring, reported more burn-related social problems. The association between burn-related variables and psychosocial outcomes has been mixed in the previous research. Some studies note that TBSA and scarring are associated with worse psychosocial outcomes (Karaçetin et al., 2014); yet, a meta-analysis concluded that clinical variables are not associated with psychosocial outcomes (e.g., anxiety, depression, and psychological maladjustment) in pediatric burn survivors (Noronha and Faust, 2007). Results from the current study suggest that burn-related variables may indeed be related to psychosocial outcomes and highlight a need for coping interventions to support survivors who experience more severe burn injuries. Active coping may underlie interventions that are often recommended for managing social reintegration after a severe burn (e.g., rehearsing responses in social situations, establishing contact with peer survivors; Phoenix Society, 2021). Although additional research is needed to fully understand the psychosocial impact of burn severity and skin grafts or other clinical variables in burn care, mental health interventions that emphasize coping in stressful social situations may be particularly beneficial for those survivors sustaining larger burn injuries, receiving a skin graft, or having visible scars or disfigurement.

A novel finding in the current study was the negative correlation between youth reports of burn-specific social problems and youth self-concept. It may be that youth who experience more social problems bear more negative feelings toward themselves. The previous research suggests that adolescents with negative self-concept are at a higher risk for social problems such as withdrawn behavior and internalizing problems (Ybrandt, 2008). With a larger sample, it would be possible to run analyses that examine the individual subscales of the $\mathrm{PH}-2$ to have a clearer understanding of particular concerns in self-concept for pediatric burn survivors and how coping strategies foster or ameliorate these concerns. To this end, further evaluation of how specific coping approaches are related to specific aspects of self-concept may inform targeted mental health interventions. 


\section{Limitations}

There were several factors that may have limited the results of the current study. The relatively small sample size resulted in reduced statistical power in detecting small and medium effects. Moderate associations were identified between some specific coping strategies and youth report of burn-related social problems and youth self-concept; therefore, the reduced power may have contributed to the lack of statistically significant findings. Future research should build upon this study by recruiting larger samples to achieve better statistical power and accuracy of estimates. A wide range of time elapsed since burn injury also was observed in our sample, limiting the extent to which these results can be generalized to specific populations of burn survivors. Additionally, our sample was primarily White. This unintentional lack of racial and ethnic diversity in our sample further limits the generalizability of our findings. A more diverse sample would also help highlight cultural considerations. It should also be noted that for participants selected through the registry, respondents may not have been representative of the pool of participants to which those letters were sent. The authors were unable to draw conclusions about the generalizability of these findings to other registry members as this data was unavailable for analysis. Further, this study is cross-sectional and did not allow for an evaluation of psychosocial outcomes over time. Future research would be strengthened by a longitudinal design, which would allow for evaluations of trajectory changes in psychosocial adjustment across time. Additionally, future research may wish to examine how the association between coping and social functioning changes as a function of time since the burn injury.

\section{Strengths}

The current study also demonstrated important strengths. For example, our sample was quite varied in terms of time since injury, which also was noted as a limitation. Our research design did not allow for examination of longitudinal trends within individuals but did permit a glimpse into how time since injury might related to psychosocial outcomes. An additional strength of this study was the use of both youth and parent reports of social functioning. This type of dual-report produced a more well-rounded understanding of each survivor's social functioning and reduced shared-method variance that may have increased the odds of a Type I error. Given some advantages (i.e., readability, brevity) of the BISQ, it may be useful to adapt and validate this tool with other pediatric illness populations, especially those involving appearance-related concerns. Other tools, such as the Pediatric Quality of Life Inventory (Varni et al., 1999) and the Children's Dermatology Life Quality Index (Parrish et al., 2020), include domains that measure interpersonal, social, and/or physical appearance concerns, which may be useful for validating the BISQ score. The inclusion of multiple coping strategies in relation to social functioning and self-concept was also a strength of this study, which is one of the first to measure the association between these particular psychosocial outcomes in pediatric burn survivors. As our understanding of coping develops, it would be beneficial to evaluate whether generic categories of coping that are studied across illness populations accurately reflect coping approaches used specifically in pediatric burns.

Observed associations between burn-injury variables, coping behaviors, social functioning and self-concept in this study suggest a need for psychosocial-based interventions that promote active coping and encourage further research of these specific outcomes in pediatric burn populations. Based on findings from previous studies (Holaday and McPhearson, 1997; Quezada et al., 2016), psychosocial interventions should focus on fostering positive social connections with family and peers as well as communication, social competence, problem-solving skills, selfesteem, and identification of self-worth in pediatric burn survivors. These factors are related to the development and growth of resilience - a characteristic that is essential for postburn adjustment and well-being.

\section{DATA AVAILABILITY STATEMENT}

The raw data supporting the conclusions of this article will be made available by the authors, without undue reservation.

\section{ETHICS STATEMENT}

The studies involving human participants were reviewed and approved by Allegheny Health Network Institutional Review Board and West Virginia University Institutional Review Board. Written informed consent to participate in this study was provided by the participants' legal guardian/next of kin.

\section{AUTHOR CONTRIBUTIONS}

$\mathrm{CD}, \mathrm{PE}$, and MS conceived and devised study. PE contributed to data collection. SY, PE, CA-N, and MS were involved in statistical analysis. MS, SY, and PE contributed to writing. CD, $\mathrm{CA}-\mathrm{N}$, and AA were involved in manuscript editing. All authors contributed to the article and approved the submitted version.

\section{FUNDING}

This research was supported by the West Virginia University Department of Psychology Student Research Fund.

\section{ACKNOWLEDGMENTS}

We would like to acknowledge the important contributions of the undergraduate research assistants and graduate psychology externs who helped to recruit participants and collect data for this project: "Rachel Bainbridge, Cameron Ford, Sarah Hayes, Janelle Mentrikoski, and Margo Szabo." We would also like to acknowledge the families who participated in this project, burn clinic staff, Catherine Butz, and Keri Brown Kirschman for their contributions to this research. 


\section{REFERENCES}

American Burn Association (2018). Burn Injury Fact Sheet [Fact sheet]. Available at: https://ameriburn.org/wp-content/uploads/2017/12/nbaw-factsheet_121417-1. pdf (Accessed November 01, 2020).

Andersson, G., Sandberg, S., Rydell, A. M., and Gerdin, B. (2003). Social competence and behaviour problems in burned children. Burns 29, 25-30. doi: 10.1016/S0305-4179(02)00239-5

Ayers, T. S., Sandier, I. N., West, S. G., and Roosa, M. W. (1996). A dispositional and situational assessment of children's coping: testing alternative models of coping. J. Pers. 64, 923-958. doi: 10.1111/j.1467-6494.1996.tb00949.x

Bakker, A., Maertens, K. J. P., Van Son, M. J. M., and Van Loey, N. E. E. (2013). Psychological consequences of pediatric burns from a child and family perspective: a review of the empirical literature. Clin. Psychol. Rev. 33, 361-371. doi: 10.1016/j.cpr.2012.12.006

Camisasca, E., Miragoli, S., Di Blasio, P., and Grych, J. (2017). Children's coping strategies to inter-parental conflict: the moderating role of attachment. $J$. Child Fam. Stud. 26, 1099-1111. doi: 10.1007/s10826-016-0645-9

Compas, B. E., Connor, J. K., Saltzman, H., Thomsen, A. H., and Wadsworth, M. E. (2001). Coping with stress during childhood and adolescence: problems, progress, and potential in theory and research. Psychol. Bull. 127, 87-127. doi: $10.1037 / 0033-2909.127 .1 .87$

De Sousa, A. (2010). Psychological aspects of paediatric burns: a clinical review. Ann. Burns Fire Disasters 23, 155-159.

Enlow, P. T., Kirschman, K. J. B., Mentrikoski, J., Szabo, M. M., Butz, C., Aballay, A. M., et al. (2019). The role of youth coping strategies and caregiver psychopathology in predicting posttraumatic stress symptoms in pediatric burn survivors. J. Burn Care Res. 40, 620-626. doi: 10.1093/jbcr/irz067

Gill, M. B. T. (2010). Psychosocial benefits for child burn survivors who attend summer camp. Dissertation Abstracts International: Section B: The Sciences and Engineering, 71, 2047.

Heffer, T., and Willoughby, T. (2017). A count of coping strategies: a longitudinal study investigating an alternative method to understanding coping and adjustment. PLoS One 12:e186057. doi: 10.1371/journal.pone.0186057

Hilliard, M. E., and Hood, K. K. (2011). Taking evidence-based coping skills training to the internet. Curr. Diab. Rep. 11, 464-466. doi: 10.1007/s11892-011-0221-z

Holaday, M., and McPhearson, R. W. (1997). Resilience and severe burns. J. Couns. Dev. 75, 346-356. doi: 10.1002/j.1556-6676.1997.tb02350.x

Jefferson, V., Jaser, S. S., Lindemann, E., Galasso, P., Beale, A., Holl, M. G., et al. (2011). Coping skills training in a telephone health coaching program for youth at risk for type 2 diabetes. J. Pediatr. Health Care 25, 153-161. doi: 10.1016/j.pedhc.2009.12.003

Karaçetin, G., Demir, T., Baghaki, S., Çetinkale, O., and Yüksel, M. E. (2014). Psychiatric disorders and their association with burn-related factors in children with burn injury. Ulus. Travma Acil Cerrahi Derg. 20, 176-180. doi: $10.5505 /$ tjtes.2014.49033

Kazis, L. E., Marino, M., Ni, P., Bori, M. S., Amaya, F., Dore, E., et al. (2017). Development of the life impact burn recovery evaluation (LIBRE) profile: assessing burn survivors' social participation. Qual. Life Res. 26, 2851-2866. doi: $10.1007 / \mathrm{s} 11136-017-1588-3$

Koon, K. S. (1993). Relationship of self-esteem in pediatric burn patients to other psychological and physiological parameters. Dissertation Abstracts International, 53, 4958.

Krishnamoorthy, V., Ramaiah, R., and Bhananker, S. M. (2012). Pediatric burn injuries. Int. J. Crit. Ill. Inj. Sci. 2, 128-134. doi: 10.4103/2229-5151.100889

Landolt, M. A., Buehlmann, C., Maag, T., and Schiestl, C. (2009). Brief report: quality of life is impaired in pediatric burn survivors with posttraumatic stress disorder. J. Pediatr. Psychol. 34, 14-21. doi: 10.1093/jpepsy/jsm088

Lavigne, J. V., and Faier-Rouman, J. (1992). Psychological adjustment to pediatric physical disorders: a meta-analytic review. J. Pediatr. Psychol. 17, 133-157. doi: 10.1093/jpepsy/17.2.133

LeDoux, J. M., Meyer, W. J., Blakeney, P., and Herndon, D. (1996). Positive self-regard as coping mechanism for pediatric burn survivors. J. Burn Care Rehabil. 17, 472-476.
Martin, S., Calabrese, S. K., Wolters, P. L., Walker, K. A., Warren, K., and Hazra, R. (2012). Family functioning and coping styles in families of children with cancer and HIV disease. Clin. Pediatr. 51, 58-64. doi: 10.1177/0009922811417300

Meijer, S. A., Sinnema, G., Bijstra, J. O., Mellenbergh, G. J., and Wolters, W. H. G. (2002). Coping styles and locus of control as predictors for psychological adjustment of adolescents with a chronic illness. Soc. Sci. Med. 54, 1453-1461. doi: 10.1016/S0277-9536(01)00127-7

Mentrikoski, J. M., Duncan, C. L., Melanson, A., Louden, E., Allgier, A., Michaud, L., et al. (2015). Factors related to the psychosocial functioning of youth with neonatal brachial plexus injuries. J. Pediatr. Psychol. 40, 285-296. doi: 10.1093/jpepsy/jsu086

Noronha, D. O., and Faust, J. (2007). Identifying the variables impacting postburn psychological adjustment: a meta-analysis. J. Pediatr. Psychol. 32, 380-391. doi: 10.1093/jpepsy/js1014

Pardo, G. D., García, I. M., Marrero, F. D. R. M., and Cía, T. G. (2008). Psychological impact of burns on children treated in a severe burns unit. Burns 34, 986-993. doi: 10.1016/j.burns.2008.01.016

Parrish, C., Haines, R. T., Stewart, D., Szabo, M., Caradec, J., Ziegfeld, S., et al. (2020). Assessing child quality of life impairments following pediatric burn injuries: rasch analysis of the children's dermatology life quality index. Qual. Life Res. 29, 1083-1091. doi: 10.1007/s11136-019-02380-w

Phoenix Society (2021). Phoenix SOAR.

Piers, E. V., and Herzberg, D. S. (2002). Piers-Harris 2. Piers-Harris Children's Self Concept Scale. 2nd Edn. Los Angeles, CA: Western Psychological Services (WPS).

Quezada, L., González, M. T., and Mecott, G. A. (2016). Explanatory model of resilience in pediatric burn survivors. J. Burn Care Res. 37, 216-225. doi: 10.1097/BCR.0000000000000261

Rimmer, R. B., Alam, N. B., Bay, R. C., Sadler, I. J., Foster, K. N., and Caruso, D. M. (2015). The reported pain coping strategies of pediatric burn survivors-does a correlation exist between coping style and development of anxiety disorder? J. Burn Care Res. 36, 336-343. doi: 10.1097/BCR.0000000000000109

Smith, T. F., Russell, H. F., Kelly, E. H., Mulcahey, M. J., Betz, R. R., and Vogel, L. C. (2013). Examination and measurement of coping among adolescents with spinal cord injury. Spinal Cord 51, 710-714. doi: 10.1038/sc.2013.65

Trask, P. C., Paterson, A. G., Trask, C. L., Bares, C. B., Birt, J., and Maan, C. (2003). Parent and adolescent adjustment to pediatric cancer: associations with coping, social support, and family function. J. Pediatr. Oncol. Nurs. 20, 36-47. doi: 10.1053/jpon.2003.5

Varni, J. W., Seid, M., and Rode, C. A. (1999). The PedsQL ${ }^{\mathrm{TM}}$ : measurement model for the pediatric quality of life inventory. Med. Care 37, 126-139. doi: 10.1097/00005650-199902000-00003

Willebrand, M., Sveen, J., Ramklint, M. M., Bergquist, R. M., Huss, M. F., and Sjöberg, M. F. (2011). Psychological problems in children with burnsparents' reports on the strengths and difficulties questionnaire. Burns 37, 1309-1316. doi: 10.1016/j.burns.2011.08.003

Ybrandt, H. (2008). The relation between self-concept and social functioning in adolescence. J. Adolesc. 31, 1-16. doi: 10.1016/j.adolescence.2007.03.004

Conflict of Interest: The authors declare that the research was conducted in the absence of any commercial or financial relationships that could be construed as potential conflict of interest.

Publisher's Note: All claims expressed in this article are solely those of the authors and do not necessarily represent those of their affiliated organizations, or those of the publisher, the editors and the reviewers. Any product that may be evaluated in this article, or claim that may be made by its manufacturer, is not guaranteed or endorsed by the publisher.

Copyright (๑ 2021 Snider, Young, Enlow, Ahrabi-Nejad, Aballay and Duncan. This is an open-access article distributed under the terms of the Creative Commons Attribution License (CC BY). The use, distribution or reproduction in other forums is permitted, provided the original author(s) and the copyright owner(s) are credited and that the original publication in this journal is cited, in accordance with accepted academic practice. No use, distribution or reproduction is permitted which does not comply with these terms. 